\title{
Competência em Informação: conceitos, características e desafios
}

Kelley Cristine Gonçalves Dias Gasque

\begin{abstract}
Resumo
A Profa. Dra. Kelley Cristine Gonçalves Dias Gasque, especialista em competência informacional, aborda e esclarece distintos conceitos desta temática ainda em construção, apresentando um breve histórico e os principais modelos aceitos para o desenvolvimento da competência informacional em ambientes os mais diversos; e suas consequências para os individuos envolvidos. A Dra. Kelley Cristine complementa suas considerações explorando os efeitos do big data e do linked data nos processos de aprendizagem contínua e fornece interessantes insights para a temática nos próximos 5-10 anos.
\end{abstract}

\section{Palavras-chave}

Letramento informacional. Alfabetização informacional. Competência informacional. Habilidade informacional. Aprendizagem cognitiva.

1. Há diferenças - e em caso afirmativo, como se manifestam essas diferenças - entre os conceitos de Competência informacional, Letramento informacional, Alfabetização informacional, e Competência em informação?

Existem diferenças entre os conceitos de competência Informacional, letramento Informacional, habilidades e alfabetização Informacional, porém esses conceitos estão inter-relacionados. Convém ressaltar que o letramento informacional é um tópico de estudo relativamente novo e, por isso, tem suscitado discussões terminológicas, em especial, em relação à tradução dos conceitos da língua inglesa para o português do Brasil. Importante lembrar que a adoção de um arcabouço conceitual relaciona-se às concepções, paradigmas e experiências do pesquisador. As diferenças entre os referidos conceitos são apresentadas considerando-se as pesquisas desenvolvidas nas áreas de Educação e Ciência da Informação. Para tanto, as pesquisas de Magda Soares fornecem subsídios importantes.

Letramento informacional: processo de aprendizagem voltado para o desenvolvimento de competências para buscar e usar a informação na resolução de problemas ou tomada de decisões. $\mathrm{O}$ letramento informacional é um processo investigativo, que propicia o aprendizado ativo, independente e contextualizado; o pensamento reflexivo e o aprender a aprender ao longo da vida. Pessoas letradas têm capacidade de tomar melho- res decisões por saberem selecionar e avaliar as informações e transformá-las em conhecimento aplicável.

Alfabetização informacional: refere-se à primeira etapa do letramento informacional, isto é, abrange os contatos iniciais com as ferramentas, produtos e serviços informacionais. Nessa etapa, o indivíduo desenvolve noções, por exemplo, sobre a organização de dicionários e enciclopédias, de como as obras são produzidas, da organização da biblioteca e dos significados do número de chamada, classificação, índice, sumário, autoria, bem como o domínio das funções básicas do computador - uso do teclado, habilidade motora para usar o mouse, dentre outros. O ideal é que a alfabetização informacional se inicie na educação infantil.

Competência informacional: refere-se à capacidade do aprendiz de mobilizar o próprio conhecimento que o ajuda a agir em determinada situação. Ao longo do processo de letramento informacional, os aprendizes desenvolvem competências para identificar a necessidade de informação, avaliá-la, buscá-la e usá-la eficaz e eficien- 
temente, considerando os aspectos éticos, legais e econômicos.

Habilidade informacional: realização de cada ação específica e necessária para alcançar determinada competência. Para o aprendiz ser competente em identificar as próprias necessidades de informação, por exemplo, é necessário desenvolver habilidades de formular questões sobre o que deseja pesquisar, explorar fontes gerais de informação para ampliar o conhecimento sobre o assunto, delimitar o foco, identificar palavraschave que descrevem a necessidade de informação, dentre outras.

Em outras palavras, grosso modo, pode-se compreender o letramento como processo de apren- dizagem a ser realizado, preferencialmente, de forma sistematizada. Nesse processo, os aprendizes devem apreender os conteúdos relacionados aos padrões de letramento e aplicá-los para resolver problemas. No início do processo, em geral, começam os primeiros contatos com os conceitos do universal informacional, o qual se denomina alfabetização informacional. Mais adiante, as atividades planejadas de ensino-aprendizagem e a experiência do aprendiz possibilitam que os conceitos tornem-se mais consolidados e aplicáveis. O conhecimento torna-se funcional, ou seja, não é mais algo abstrato, mas um meio para resolver problemas e tomar decisões. Esses conhecimentos aplicáveis ou saber fazer são as competências. Evidentemente, não se adquire competências sem desenvolver habilidades específicas.

\section{Quais são os predecessores ou áreas basilares da pesquisa voltada para a "Competência em Informação"?}

O letramento informacional (LI) tem raízes nas áreas de treinamento, formação e educação de usuários. Na década de 1930, por exemplo, os termos relacionados ao ensino dos recursos das bibliotecas eram usuais no vocabulário angloamericano. No Brasil, esses estudos começaram a surgir a partir da década de 1970, com a preocupação de ensinar os usuários a usarem os recursos das bibliotecas.

O conceito de letramento informacional foi introduzido por Paul Zurkowski, presidente da US Information Industry Association, em 1974, em um relatório submetido à National Commission on Libraries and Information Science (NCLIS). No documento, ele recomendava o desenvolvi-

mento de um programa nacional de letramento informacional para as décadas seguintes. Para ele, pessoas com capacidade para usar os recursos de informação poderiam ser consideradas letradas.

O letramento, portanto, abrange o ensino dos recursos das bibliotecas, mas não se restringe a elas, pois considera que as pessoas ao longo da vida buscam e usam informação constantemente em vários canais e fontes de informação.

As disciplinas que mais contribuem para o desenvolvimento do letramento são educação, psicologia, comportamento informacional humano e metodologia científica.

3. Em linhas gerais, quais são os modelos já validados e os principais aspectos que contribuem para o desenvolvimento/estímulo da Competência em Informação? Como são aceitos/ utilizados nas organizações da esfera pública? E na esfera privada?

No final da década de 1980 surgem as definições e padrões de letramento para a educação básica e ensino superior e, em paralelo com os padrões da educação básica, a abordagem do Big Six Skills, desenvolvido por Eisenberg e Berkowitz. Além desses, há vários modelos como o ciclo de pesquisa (MCKENZIE, 1999), o modelo de Alberta (OBERG, 1999), os sete pilares do letramento informacional (SCONUL..., 2011), o modelo de Kuhlthau (1999) e muitos outros. Muitos modelos de LI são similares ou abrangem etapas do método científico.

Na primeira década do século XX, John Dewey, psicólogo estadunidense, percebeu que a aprendizagem poderia ser mais eficiente se alicerçada no 
método científico, o qual propicia o pensar reflexivo. Ou seja, o aprender vincula-se à compreensão do conteúdo de aprendizagem no contexto real, em que é possível vê-lo em suas relações com as outras coisas, isto é, compreender como determinado aspecto funciona, que consequências traz, suas causas e possíveis aplicações. Essa forma reflexiva de aprender possui potencial para estimular o desenvolvimento do letramento informacional.

A literatura educacional mostra que a melhor forma de ensinar é por meio de resolução de problemas e projetos de pesquisa. Muitos modelos de LI contemplam esse princípio, mas precisam abordar também os conteúdos conceituais, procedimentais e atitudinais de aprendizagem, ou seja, aqueles relacionados ao assunto ou problema de pesquisa, aos procedimentos de pesquisa (padrões de letramento) e às atitudes e postura ao longo do processo de aprendizagem.

Nos Estados Unidos, e em vários países da Europa, muitas escolas e universidades adotaram programas de letramento informacional. Alguns de forma transversal, outros por meio da introdução de uma ou duas disciplinas, e ainda há aqueles que adotaram os projetos de trabalho como concepção curricular, tal qual sugeriu John Dewey. A forma de implantar o programa se relaciona com a concepção de ensino-aprendizagem da instituição, à formação docente, à compreensão da cultura institucional, bem como à estrutura curricular e à infraestrutura de informação disponível. No Brasil, os programas de letramento informacional, quando existem, ainda são incipientes. Contudo, a tendência é de ampliação, em especial com a expectativa de melhorar a produção do conhecimento.

\section{Como se configura atualmente o cenário/espaço para pesquisa de "Competência em Informação" e qual é o principal alvo/objeto de pesquisa dessa área no Brasil?}

No Brasil, os estudos começaram por volta de 2000. Houve grande expansão nos últimos anos, mas a caminhada ainda encontra-se em fase inicial. As pesquisas são, em sua maioria, de natureza exploratória e buscam compreender melhor o significado do conceito e dos termos relacionados; verificar a aplicação de modelos LI nas organizações; identificar o potencial do processo na aprendizagem, por exemplo. Algumas instituições começam a discutir a adoção do referido processo e identificar os obstáculos para sua implantação. Pode se observar que o assunto desperta interesse das instituições acadêmicas, dos professores e, ao mesmo tempo, traz muitos questionamentos e dúvidas.

Pode-se verificar que as pesquisas sobre letramento informacional, bem como os materiais de ensino disponíveis na web estão centrados mais nos padrões relacionados à identificação da necessidade e busca da informação do que no uso da informação. A hipótese provável é que a formação dos bibliotecários nem sempre contempla os aspectos psicopedagógicos e didáticos necessários.

\section{Como os conceitos de big data e as tecnologias da web semântica (tais como os dados abertos interligados/linked open data) afetam os processos de aprendizagem contínua?}

O conceito do big data não é consensual. Pode ser compreendido como as múltiplas fontes de informação estruturadas e não estruturadas que não foram capturadas pelas ferramentas típicas dos bancos de dados, bem como conjunto de software para tratamento dos dados. Por sua vez, os dados abertos interligados objetivam criar conexões entre vários dados, em especial, aqueles disponíveis em bibliotecas, museus e arquivos, criando uma grande rede estruturada semanticamente legível. Ao se buscar, por exemplo, Dom Casmurro de Machado de Assis, dados de várias bibliotecas e museus que estão integrados podem ser acessados.

Não há dúvidas de que nunca foram produzidas tantas informações quanto na sociedade contemporânea e que as tecnologias possibilitam lidar 
melhor com a massa informacional. O big data e o linked data farão parte da infraestrutura da web, onde os dados estarão disponíveis e identificados. Contudo, para que essas tecnologias tragam inovação e conhecimento é necessário que as pessoas saibam o que fazer com as informações, isto é, a tomada de decisão é um processo cogni- tivo que depende do ser humano. Dessa forma, o direito e o acesso ao conhecimento deve incluir o conhecimento de como se aprende (a metacognição), e as estratégias e ferramentas cognitivas necessárias para apreensão de novos conhecimentos em domínios específicos.

\section{Quais são os temas/abordagens/aplicações emergentes da "Competência em Informação" para os próximos $5 / 10$ anos?}

Os horizontes são amplos. Há muito o que fazer, em especial, no que concerne à implantação dos programas de LI nas instituições educacionais, de pesquisa e em empresas. Desde este ponto de vista, alguns temas emergentes são: a formação de professores e bibliotecários para o letramento informacional; o aprofundamento das questões relacionadas ao ensino-aprendizagem, por exemplo, e aos processos psicopedagógicos e didáticos; o desenvolvimento de materiais de ensino e objetos de aprendizagem; a relação do LI com o ensino a distância; as dificuldades de aprendizagem e avaliação no processo de LI; o gerenciamento e monitoração do processo de LI; dentre outros.

7. Como a Competência em Informação pode contribuir para uma atitude mais autônoma/ proativa de busca da informação por parte dos usuários em meio à imensidade e multiplicidade de recursos disponíveis na web?

Os indivíduos letrados dominam estratégias de buscas e de uso da informação mais eficazes e eficientes, bem como possuem postura mais crítica e reflexiva nas e sobre as atividades de LI. Tais

\section{Referências}

\section{EISENBERG, M.; BERKOWITZ, L. Information} problem-solving. New Jersey: Ablex, 1990.

\section{GASQUE, K. C. G. D. Letramento}

informacional: pesquisa, reflexão e aprendizagem. Brasília: Faculdade de Ciência da Informação, 2012. 178 p.

\section{GASQUE, K. C. G. D. Arcabouço conceitual} do Letramento Informacional. Ciência da Informação, v. 39 n. 3, p.83-92, set./dez., 2010. Disponível em: <http://www.scielo.br/ pdf/ci/v39n3/v39n3a07.pdf $>$. Acesso em: 23 jul. 2013.

\section{GASQUE, K. C. G. D.; TESCAROLO, R.}

Desafios educacionais para implementação do letramento informacional na Educação Básica. Educação em Revista, v. 26, n.1, p. competências podem gerar sentimentos de segurança, otimismo, confiança e contribuir para promoção de atitudes autônomas e proativas.

41-56, abr. 2010. Disponível em: <http:// www.scielo.br/pdf/edur/v26n1/03.pdf >. Acesso em: 23 jul. 2013.

GASQUE, K C. G. D.; CUNHA, M. V. da. A epistemologia de John Dewey e o letramento informacional. Transinformação, v. 22, n. 2, p. 139-146, maio/ago. 2010. Disponível em: $<$ http://periodicos.puc-campinas. edu.br/seer/index.php/transinfo/article/ view/491/471>. Acesso em: 23 jul. 2013.

KUHLTHAU, C. C. Accommodating the user's information search process: challenges for information retrieval system designers.

Bulletin of the American Society for the information Science, v. 25, n. 3, Feb. 1999. Disponível em: <http://www.asis.org/ Bulletin/Feb-99/kuhlthau.html>. Acesso em: 23 jul. 2013. 
LIMA JUNIOR, W. T. Big Data, Jornalismo Computacional e Data Journalism: estrutura, pensamento e prática profissional na web de dados. Estudos em Comunicação, n. 12, p. 207-222, dez. 2012. Disponível em: <http:// www.ec.ubi.pt/ec/12/pdf/EC12-2012Dez-11. pdf $>$. Acesso em: 23 jul. 2013.

MCKENZIE, J. The research cycle. The Educational Technology Journal, v. 9, n. 4, 1999. Disponível em:<http://www.fno.org/ dec99/rcycle.htm>. Acesso em: 25 jul. 2013.

OBERG, D. Teaching the research process: for discovery and personal growth. In: IFLA COUNCIL AND GENERAL CONFERENCE, 65., 1999, Bangkok, Thailand. Proceedings... Bangkok: IFLA, 1999. Disponível em: <http:// archive.ifla.org/IV/ifla65/papers/078-119e. htm>. Acesso em: 23 jul. 2013.

\section{SANTOS NETO, A. L. dos; MARCONDES,} C. H.; PEREIRA, D. V.; FONSECA, E. R.; SOUZA, I. V. P. de; BARBOSA, N.; MORAES, R. P. T. de; MARTINS, S. C. Tecnologias de dados abertos para interligar bibliotecas, arquivos e museus: um caso machadiano.

Transinformação, v. 25, n. 1, abr. 2013. Disponível em: <http://dx.doi.org/10.1590/ S0103-37862013000100008>. Acesso em: 23 jul. 2013.

SCONUL Working Group on Information Literacy. The SCONUL Seven Pillars of Information Literacy. Apr. 2011. Disponível em: <http://www.sconul.ac.uk/sites/default/ files/documents/coremodel.pdf $>$. Acesso em: 23 jul. 2013.

SOARES, M. Letramento e alfabetização: as muitas facetas. Revista Brasileira de Educação, n. 25, jan /abr 2004. Disponível em: <http://www. scielo.br/pdf/rbedu/n25/ n25a01.pdf $>$. Acesso em: 19 jul.2013.

SOARES, M. Letramento: um tema em três gêneros. Belo Horizonte: Autêntica, 1998.
Information Literacy: Concepts, characteristics and challenges

\section{Abstract}

Dr. Kelley Cristine Gonçalves Dias Gasque is an Information Literacy specialist who addresses and explains different concepts of a topic that is still being built. She presents a brief history and the accepted key models for the development of information literacy in the most diverse environments; and its consequences for those involved. Dr. Kelley Cristine complements her considerations exploring the effects of big data and linked data in the process of continuous learning provinding interesting insights into the topic in the next 5-10 years.

\section{Keywords}

Information literacy. Information skills. Cognitive learning.

Kelley Cristine é Professora Adjunta da graduação e pós-graduação stricto sensu da Faculdade de Ciência da Informação da Universidade de Brasilia (UNB). Tem Doutorado (2008) e Mestrado (2003) em Ciência da Informação pela UNB; especialização em Literatura Brasileira

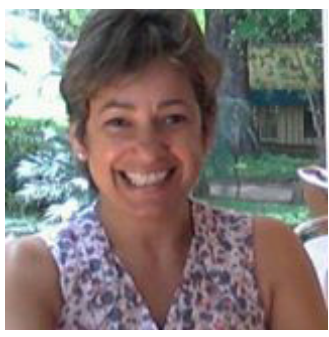
pela Universidade Católica de Brasília (1999); e graduação em Biblioteconomia e Documentação (1996) também pela UNB. Durante 11 anos de trabalho no Colégio Marista de Brasilia exerceu as funções de bibliotecária e, posteriormente, de assessora do Núcleo Tecnologia da Informação e Núcleo Psicopedagógico ( $2^{\circ}$ ao $5^{\circ}$ ano), bem como projetou e coordenou 0 Centro de Recursos de Aprendizagem (CRA). Atua nos temas de letramento informacional, comunicação cientifica, comportamento informacional (estudos de usuários), aprendizagem, leitura, formação de professores, bibliotecas escolares e objetos de aprendizagem. Além de publicar artigos, textos em jornais/revistas, capítulos de livros e livros completos, apresenta e discute os temas de sua especialidade nos seguintes canais da Internet:

»http://kelleycristinegasque.blogspot.com.br

»https://www.facebook.com/pages/Grupo-de-

Pesquisa-Competência-InformacionalLetramentoinformacional/308431162587554

Como citar este documento:

GASQUE, K. C. G. D. Competência em Informação: conceitos, características e desafios. AtoZ: novas práticas em informação e conhecimento, Curitiba, v. 2, n. 1, p. 5-9, jan./jun. 2013. Disponivel em: <http://www.atoz.ufpr.br>. Acesso em: .Entrevista. 